\title{
Awareness, Support, and Perceived Impact of the Connecticut Pesticide Ban
}

\author{
Julie H. Campbell ${ }^{1}$ and Victoria H. Wallace ${ }^{2}$
}

\begin{abstract}
AdDitIONAL INDEX WORDs. child health, pesticide restriction, school policy, survey, turfgrass

SUMMARY. Concern over the use of pesticides in public areas, such as schools, daycare centers, and parks, has prompted some state and local governments to severely restrict or ban pesticides in these locations. Connecticut currently has bans for daycare centers, school grounds with kindergarten through eighth grade classes, and playgrounds in municipal parks. This study was designed to understand general public awareness of these bans and the public sentiment for these additional bans. An online survey was conducted in late 2016 asking Connecticut residents about their levels of awareness of the current pesticide bans, and whether they supported the current ban or would support additional bans. Demographics and other individual characteristics/perceptions are used to explain whether a respondent knows there is a pesticide ban and if the respondent thinks there should be a pesticide ban. Only $7 \%$ of the respondents could correctly identify where pesticide bans are currently in place, with most respondents being unsure $(74 \%)$ if a ban was, in fact, in place. No respondents correctly identified the location of the ban without also identifying an incorrect location as well. A large percentage of respondents indicated the state should have a pesticide ban, with those respondents supporting a ban across all locations listed. Pesticide bans on school grounds and athletic fields from kindergarten to 12th grade were strongly supported, with scores ranging from 85.9 to 86.6 on a 100 -point scale, with 100 representing extreme support for pesticide bans. The results indicate that general awareness of the current pesticide ban, as well as knowledge of where current bans are in place, is low. Most respondents support a statewide ban that exceeds current Connecticut law.
\end{abstract}

S ynthetic pesticides are often used across the United States on public athletic fields and park areas to control weeds and various other pests. On these public recreational areas, the public is frequently unaware where a pesticide application has been made or which pesticide has been applied. Although some state laws require posting of a pesticide application, the allowable reentry period after an application varies with the product used.

There is a general increase in concern about the use of pesticides on landscapes and athletic fields. This concern has come about due to research showing pesticide exposure having a positive association with

Received for publication 22 Aug. 2019. Accepted for publication 18 Nov. 2019.

Published online 15 January 2020.

${ }^{1}$ Department of Horticulture, University of Georgia, 325 Hoke Smith Building, Athens, GA 30602

${ }^{2}$ Department of Extension, University of Connecticut, 562 New London Turnpike, Norwich, CT 06360

J.H.C. is the corresponding author. E-mail: julie. campbell@uga.edu.

This is an open access article distributed under the CC BY-NC-ND license (https://creativecommons.org/ licenses/by-nc-nd/4.0/).

https://doi.org/10.21273/HORTTECH04493-19 some forms of cancer (Bassil et al., 2007; Parrón et al., 2014); however, there is contrasting research that shows no linkage between pesticide exposure and cancer incidence in varying situations (De Roos et al., 2005; Niehoff et al., 2016). Furthermore, public concern has increased as lawsuits against pesticide manufacturers have made headlines. Perhaps the most well-known lawsuit is against Bayer AG (Pittsburgh, PA) and its product Roundup, whereby a lawsuit alleges that Roundup's active ingredient glyphosate is a carcinogen (Bellon, 2019).

Furthermore, the use of pesticides for the maintenance of school grounds has become a mounting point of concern because of the potential health impacts on citizens, particularly children, who may be exposed to the pesticides (Alarcon et al., 2005; Gilden et al., 2012). Currently, there is no evidence linking childhood cancer to pesticide exposure on school grounds or athletic fields (Chen et al., 2015; Gilden et al., 2012; Morgan et al., 2005; Niehoff et al., 2016). Notably, Chen et al. (2015) found no association between outdoor pesticide exposure and cancer, but increased cancer incidence with increased indoor pesticide exposure.

Although the linkage between pesticide exposure and health risks is not definitive, the rising public concern has led administrators and public policymakers to change public policy, whether warranted or not (Millington and Wilson, 2014). Notably, some state and local governments have severely restricted or banned pesticide use on school grounds, public areas, and even home lawns (Bachand and Gue, 2011; Hall, 2015; Hurley et al., 2014; Kowalewski et al., 2016; Owens, 2009; Sissell, 2005). In 2009, Ontario, Canada, passed the Cosmetic Pesticides Ban Act, which outlawed the use of pesticides for cosmetic purposes on lawns, gardens, hardscape surfaces, cemeteries, schools, and parks (Ontario Ministry of the Environment, 2009). Two U.S. states, Connecticut and New York, have completely banned pesticide usage on kindergarten to eighth grade school grounds (the New York ban is for grades kindergarten to 12), and at least 38 additional states have bans or limitations on the use of pesticides on school grounds (Hurley et al., 2014). The Connecticut ban took effect 1 July 2010 and applies to both public and private schools where kindergarten to eighth grades are present, as well as daycare centers (Connecticut General Assembly, 2009). On 1 Oct. 2015, the ban was extended to municipal playgrounds (Connecticut General Assembly, 2015).

As states put pesticide prohibitions in place, it is essential to gauge public awareness about pesticide bans, as well as to understand residents' feelings and beliefs about the laws and other potential pesticide bans. Therefore, this research attempts to assess Connecticut residents' awareness of the current pesticide ban. It also identifies these residents' sentiments about the ban and the extent to which it should be applied. This study hypothesizes that residents currently have little awareness about the enacted pesticide ban; however, there would likely be wide support for a ban if the primary location was often frequented by children. This study takes a cursory look at which locations survey respondents believe a pesticide ban should be implemented. 


\section{Materials and methods}

To assess awareness and support for the Connecticut pesticide ban, an online survey was implemented during Summer/Fall 2016. The survey targeted Connecticut residents who were 18 years or older. Survey respondents originated from the panel database of Lightspeed Global Market Insite, Inc. (Warren, NJ). Approximately 1200 residents completed the survey, with $\approx 1050$ answering the pesticide law awareness section. After entering the survey, respondents were asked a variety of purchasing-related questions associated with horticultural products, then respondents were asked about their views on the Connecticut pesticide law. Notably, respondents were asked whether a pesticide ban was currently in place, whether there should be a pesticide ban, and where a ban should be imposed.

After completing the pesticide ban questions, respondents were asked demographic (e.g., age, household income) questions, as well as questions about their political leanings (i.e., Democrat, Republican, other), trust in the state government to provide accurate information about a state pesticide ban (i.e., 100 -point scale on $0=$ distrust, $50=$ neither trust/distrust, $100=$ trust), and political leanings associated with their views on the environment (i.e., 100 -point scale on $0=$ liberal, $50=$ neither liberal/conservative, $100=$ conservative).

The sample's median age was 45 years with a median household income in 2015 of just under $\$ 73,000$ (Table 1). Eighty-one percent of the survey sample respondents were Caucasian, with the average household size $\approx 2.7$ people. The U.S. Census estimated median age in Connecticut is 41 -years-old with a median household income of $\$ 73,781$ (U.S. Census Bureau, 2019). Furthermore, the U.S. Census Bureau (2019) also estimates the Connecticut population is $80 \%$ Caucasian with 2.6 people per household. Given the U.S. Census estimates, the survey sample is fairly representative of the Connecticut population, with the exception of an overrepresentation of women.

A multinomial logit model (MNL) was used to determine which factors may influence a respondent's level of awareness of the pesticide ban. The MNL model (Greene, 2012) was specified as follows:

$$
P\left(R_{i}=j\right)=\frac{e^{\beta_{j}^{\prime} x_{i}}}{\sum_{v=1}^{3} e^{\beta_{v}^{\prime} x_{i}}} \text {, where } j=1,2,3
$$

where $P\left(R_{i}=j\right)$ is the probability that respondent $i$ 's awareness level $j$ (i.e., there is a pesticide ban, there is not a pesticide ban, or they did not know); $v$ is a set of demographics and individual characteristics/perceptions (Table 1 ); and $\beta$ is a vector of parameters. The $\beta$ parameter estimates from the MNL model represent log-odds, so the marginal effects were calculated. The resulting marginal effects have different interpretations, depending on whether the variable is continuous or categorical. Continuous variables are interpreted as a percent increase/ decrease in the probability of group membership, given a l-unit increase in the mean of the explanatory variable. However, categorical variables are interpreted as a percent increase/decrease in the probability of group membership, given a change from the base category to the category of interest (e.g., male to female).

Table 1. Descriptive summary statistics of Connecticut residents participating in a 2016 online survey on pesticide bans within the state of Connecticut.

\begin{tabular}{|c|c|c|}
\hline Variable & Mean & SD \\
\hline Age (median in years) & 45 & - \\
\hline Caucasian $(\%)$ & 81 & 39 \\
\hline Male $(\%)$ & 27 & 45 \\
\hline \multicolumn{3}{|l|}{ Political leaning $(\%)$} \\
\hline Republican & 22 & 41 \\
\hline Democrat & 29 & 46 \\
\hline Other & 48 & 50 \\
\hline \multicolumn{3}{|l|}{ Urbanicity (\%) } \\
\hline Rural & 23 & 42 \\
\hline Suburban & 64 & 48 \\
\hline Urban & 13 & 33 \\
\hline \multicolumn{3}{|l|}{ People in household (no.) } \\
\hline Adults & 2.2 & 1.1 \\
\hline Children $(\leq 18$ years $)$ & 0.5 & 0.9 \\
\hline Household income in 2015 (median) & $\$ 73,000$ & - \\
\hline \multicolumn{3}{|l|}{ Education $(\%)$} \\
\hline High school or less & 20 & 40 \\
\hline 2 years or some college & 34 & 48 \\
\hline Bachelor's or greater & 45 & 50 \\
\hline $\begin{array}{l}\text { Trust information provided by state government } \\
\text { regarding a pesticide ban }(0-100 \text { scale })^{z}\end{array}$ & 47.2 & 27.3 \\
\hline Political view on environment $(0-100 \text { scale })^{y}$ & 49.2 & 25.6 \\
\hline Maintain a landscape $(\%)$ & 65 & 48 \\
\hline
\end{tabular}

After estimating the parameters and marginal effects for the awareness model (i.e., there is a pesticide ban, there is not a pesticide ban, or they did not know) an MNL model with the same specification as Eq. [1] was estimated. The dependent variable in that model is whether there should be a statewide pesticide ban in Connecticut (i.e., yes, no, not sure). The same explanatory variables were used for each model.

\section{Results}

Only $7 \%$ of survey respondents were aware there is a current legislated pesticide ban in Connecticut (Table 2). Most respondents were not sure $(74 \%)$ if there was a ban in place. The remaining $19 \%$ of respondents incorrectly indicated that Connecticut did not have any pesticide ban in place. Of those respondents who correctly indicated there was a current pesticide ban, none were totally correct in their identification of the locations where the ban is enacted. Twenty-six percent of the respondents who were aware of a ban were unsure as to where the ban is in effect. These respondents correctly identified ban locations, but also indicated that the ban applied to some 
additional locations where it is not in place. When asked whether there should be a pesticide ban in Connecticut, $50 \%$ of respondents indicated that there should be a ban, whereas $15 \%$ responded that there should not be a ban.

AWARENESS OF A STATE-MANDATED PESTICIDE BAN. With respect to the MNL results, as household income increased by $\$ 10,000$ from the mean income, a respondent was $0.3 \%$ less likely to be aware that a pesticide ban currently exists in Connecticut (Table 3). So in essence, respondents with higher incomes were less likely to be aware of the current state pesticide ban. On the other hand, a respondent was $0.5 \%$ more likely to believe a pesticide ban was not in place as

Table 2. Connecticut residents' awareness of a pesticide ban within the state of Connecticut using data from a 2016 online survey.

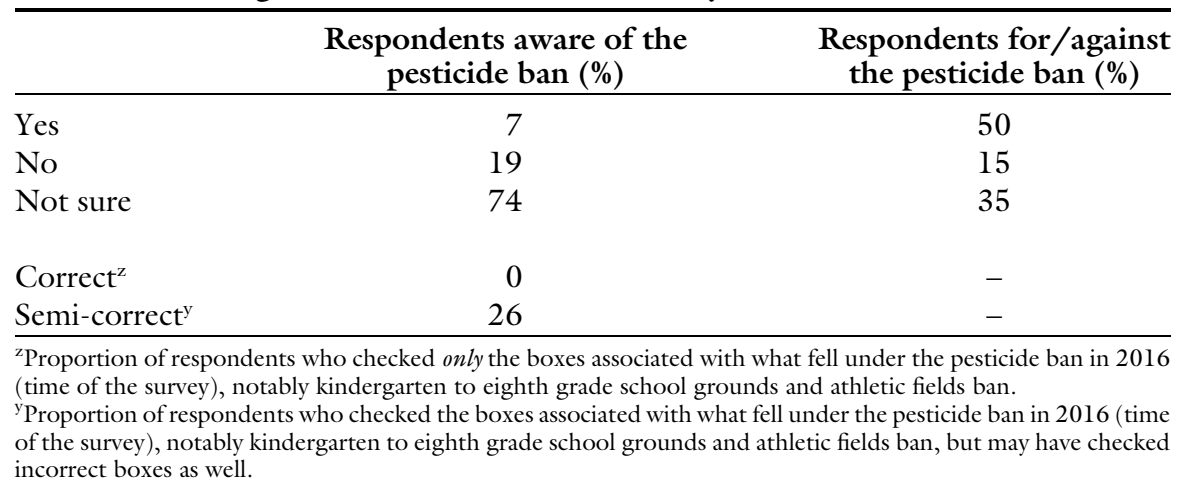

household income increased by $\$ 10,000$. This means that higher incomes were more likely to believe that there is no pesticide ban in Connecticut. Suburban respondents were less likely to be aware of the state-mandated pesticide ban than respondents who lived in urban areas. Those respondents who trust the state government to provide accurate information about a state pesticide ban or have more conservative political views on environmental issues were more likely to be aware of the current pesticide ban. Males were $10.4 \%$ less likely to not be sure about a ban, and were $9.2 \%$ more likely to believe there was no pesticide ban. As the number of children in a household increased, a respondent was $2.7 \%$ more likely to believe there was no pesticide ban in Connecticut.

Although $7 \%$ of respondents indicated there was a state-mandated pesticide ban, there is a wide discrepancy about where the ban is actually

Table 3. Marginal effects associated with the multinomial logit model to determine if characteristics of Connecticut residents affected their awareness of the Connecticut pesticide ban.

\begin{tabular}{|c|c|c|c|c|c|c|c|c|c|}
\hline & \multicolumn{9}{|c|}{ Awareness of the Connecticut pesticide ban } \\
\hline & \multicolumn{3}{|c|}{ Yes } & \multicolumn{3}{|c|}{ No } & \multicolumn{3}{|c|}{ Not sure } \\
\hline & Marg. eff. ${ }^{\mathrm{z}}$ & SE & $P$ & Marg. eff. & SE & $P$ & Marg. eff. & SE & $P$ \\
\hline Caucasian & -0.027 & 0.021 & 0.196 & 0.007 & 0.035 & 0.842 & 0.020 & 0.038 & 0.597 \\
\hline Male & 0.012 & 0.015 & 0.414 & 0.092 & 0.029 & 0.002 & -0.104 & 0.031 & 0.001 \\
\hline Household income in $2015^{y}$ & -0.003 & 0.000 & 0.099 & 0.005 & 0.000 & 0.023 & -0.002 & 0.000 & 0.365 \\
\hline Bachelor's or greater & 0.029 & 0.020 & 0.153 & -0.009 & 0.035 & 0.792 & -0.020 & 0.039 & 0.607 \\
\hline \multicolumn{10}{|l|}{ People in household (no.) } \\
\hline Adults & -0.004 & 0.007 & 0.532 & -0.005 & 0.012 & 0.692 & 0.009 & 0.013 & 0.492 \\
\hline Children ( $\leq 18$ years $)$ & -0.012 & 0.008 & 0.151 & 0.027 & 0.012 & 0.026 & -0.015 & 0.014 & 0.280 \\
\hline Maintain a landscape & 0.026 & 0.012 & 0.035 & 0.123 & 0.024 & 0.000 & -0.149 & 0.026 & 0.000 \\
\hline Republican & -0.009 & 0.018 & 0.611 & 0.033 & 0.038 & 0.388 & -0.024 & 0.041 & 0.566 \\
\hline Other & -0.000 & 0.015 & 0.998 & -0.027 & 0.029 & 0.359 & 0.027 & 0.032 & 0.398 \\
\hline $\begin{array}{l}\text { Trust information provided } \\
\text { by state government regarding } \\
\text { a pesticide ban }(0-100 \mathrm{scale})^{\mathrm{x}}\end{array}$ & 0.001 & 0.000 & 0.033 & 0.000 & 0.000 & 0.923 & -0.001 & 0.001 & 0.234 \\
\hline $\begin{array}{l}\text { Political view on environment } \\
\quad(0-100 \text { scale })^{\mathrm{w}}\end{array}$ & 0.001 & 0.000 & 0.059 & 0.000 & 0.001 & 0.967 & -0.001 & 0.001 & 0.309 \\
\hline Log pseudolikelihood & \multicolumn{9}{|c|}{-705.045} \\
\hline$P>\chi^{2}$ & \multicolumn{9}{|c|}{0.000} \\
\hline Pseudo $R^{2}$ & \multicolumn{9}{|c|}{0.065} \\
\hline Observations (no.) & \multicolumn{9}{|c|}{1,048} \\
\hline
\end{tabular}

${ }^{\mathrm{z}}$ Marginal effect.

${ }^{y}$ Household income represents a percent change given a $\$ 10,000$ change in income.

${ }^{\mathrm{x}} 0=$ distrust, $50=$ neither trust nor distrust, $100=$ trust.

${ }^{\mathrm{w}} 0=$ extremely liberal, $50=$ neither liberal nor conservative, $100=$ extremely conservative. 
implemented and where respondents perceived it to be in effect. As noted previously, the pesticide ban applies to kindergarten to eighth grade school grounds and athletic fields, as well as municipal playgrounds throughout the state; however, $40 \%$ of respondents perceived the ban to be associated with pesticides on home lawns (Table 4). Another 30\% and $27 \%$ perceived that the ban also applied to ninth through 12th grade school grounds and athletic fields, respectively. There could be some confusion by respondents because, if a property is shared by higher and lower grades, the law banning pesticides supersedes any pesticide use allowed on higher grade areas. Thus, there is essentially a ban on higher grade property in some communities because of shared use of facilities. No respondents correctly identified the location of the ban without also identifying an incorrect area. Kindergarten to eighth grade school grounds and kindergarten to eighth grade athletic fields were identified as being a location of the ban by $33 \%$ and $27 \%$ of respondents, respectively. Of the respondents indicating kindergarten to eighth grade school grounds and athletic fields, only $26 \%$ indicated both school grounds and athletic fields.

ShOuld THERE BE A STATEMANDATED PESTICIDE BAN? Even though a large percentage of respondents indicated they were not aware that a pesticide ban existed in the state, a large percentage of respondents noted that the state should have a pesticide ban (Table 2). Respondents indicating that the state should have a pesticide ban strongly supported a pesticide ban across all types of locations (Table 5). For instance, a pesticide ban on school grounds and athletic fields from kindergarten to 12th grade was strongly supported, with scores ranging from 85.9 to 86.6 on a 100-point scale, with 100 representing an extreme support for pesticide bans. Municipal and state-maintained parks also received strong support for the implementation of a pesticide ban. Although ranked lower than parks and school locations, home lawns and commercial building grounds also received strong support for a ban, with a score of 75.0 and 72.4 , respectively.

Respondents indicating there should not be state-mandated pesticide bans in Connecticut still demonstrated moderate support for bans on school grounds and athletic fields, as well as municipal and state-maintained parks. Bans aimed at reducing pesticide use on home lawns, commercial buildings, and roadways (state- and municipalmaintained) received considerably less support.

As indicated in Table 6, respondents who were parents of elementary and middle school children were generally more in favor of a pesticide ban. The percentage in favor declined when respondents were asked about a ban

Table 4. Connecticut residents' responses when asked where they believe the current Connecticut pesticide ban is located using data from a 2016 online survey. ${ }^{\mathrm{T}}$

\begin{tabular}{lc}
\hline Where residents believe there is a ban & Proportion (\%) \\
\hline Home lawn & 40 \\
Kindergarten-eighth grade school grounds (not & 33 \\
including athletic fields) & \\
9th-12th grade school grounds (not including & 30 \\
athletic fields) & \\
Kindergarten-eighth grade athletic fields & 27 \\
9th-12th grade athletic fields & 27 \\
Municipal-maintained parks & 26 \\
Municipal-maintained roadways & 10 \\
Municipal-maintained athletic fields & 31 \\
State-maintained parks & 32 \\
State-maintained roadways & 12 \\
State-maintained athletic fields & 22 \\
Commercial building grounds & 11 \\
Other & 7 \\
I do not know & 31 \\
\hline
\end{tabular}

${ }^{\mathrm{z}}$ Question was asked only to the 81 respondents who indicated Connecticut currently has a pesticide ban.

Table 5. Connecticut residents' answers to where there should be a pesticide ban implemented in the state of Connecticut using data from a 2016 online survey.

\begin{tabular}{|c|c|c|c|c|}
\hline & \multicolumn{3}{|c|}{$\begin{array}{l}\text { Residents' responses } \\
\text { to if there should be } \\
\text { a pesticide ban } \\
(0-100 \text { scale })^{\mathrm{z}}\end{array}$} & \multirow[b]{2}{*}{ Overall avg } \\
\hline & $\overline{\text { Yes }}$ & No & Not sure & \\
\hline Home lawn & 75.0 & 35.1 & 49.9 & 61.1 \\
\hline $\begin{array}{l}\text { Kindergarten-eighth grade school grounds (not } \\
\text { including athletic fields) }\end{array}$ & 86.6 & 58.5 & 70.3 & 77.2 \\
\hline $\begin{array}{l}\text { 9th-12th grade school grounds (not including } \\
\text { athletic fields) }\end{array}$ & 85.9 & 56.7 & 68.8 & 76.1 \\
\hline Kindergarten-eighth grade athletic fields & 86.4 & 59.0 & 70.7 & 77.2 \\
\hline 9th-12th grade athletic fields & 86.1 & 56.5 & 70.2 & 76.6 \\
\hline Municipal-maintained parks & 84.6 & 55.0 & 65.0 & 73.8 \\
\hline Municipal-maintained roadways & 73.3 & 39.0 & 52.5 & 61.6 \\
\hline Municipal-maintained athletic fields & 84.3 & 51.3 & 66.5 & 73.6 \\
\hline State-maintained parks & 85.3 & 53.3 & 66.8 & 74.5 \\
\hline State-maintained roadways & 71.9 & 40.3 & 52.1 & 60.9 \\
\hline State-maintained athletic fields & 84.5 & 53.7 & 66.9 & 74.3 \\
\hline Commercial building grounds & 72.4 & 39.5 & 50.9 & 60.7 \\
\hline Other & 58.3 & 39.2 & 41.9 & 49.8 \\
\hline
\end{tabular}

${ }^{\mathrm{z}} 0=$ do not support, 50 = moderately support, $100=$ extremely support. on professionally maintained turf areas. Although no current pesticide extends to collegiate or profesand $51 \%$ of respondents indicated college and professional athletic fields also should be included under a pesticide ban, respectively (Table 6).

Table 7 presents the marginal effects associated with the MNL model. Respondents who indicated they maintained a home lawn were $8.2 \%$ more likely to want state-mandated pesticide bans. Older respondents were less likely 
to believe there should be a statemandated pesticide ban, as were households with more adults. Males were $10.5 \%$ more likely to believe there should not be a pesticide ban in Connecticut. With respect to trusting the state to provide accurate information about a pesticide ban, respondents who displayed more trust were more likely to support a state pesticide ban. As trust in the state's ability to provide accurate information increased by $1 \%$ from the mean trust rating (47.2 average rating on the 100 -point scale $=$ neither trust/distrust, Table 1), a respondent was $0.2 \%$ more likely to support a state pesticide ban. As a respondent had increasingly conservative political views about the environment, the respondent was less likely to support a pesticide ban. A $1 \%$ increase in a respondent's political views on the environment rating (49.2 average rating on the 100 -point scale $=$ neither liberal/conservative) resulted in a respondent being $0.2 \%$ less likely to support a state pesticide ban.

Table 6. Connecticut residents' response to the question in a 2016 online survey: Should a state-mandated pesticide ban be imposed on various types of athletic fields?

\begin{tabular}{lllc}
\hline & Yes & No & Indifferent \\
\cline { 2 - 4 } & & $\mathbf{( \% )}$ & \\
\hline Elementary and middle school fields & 67 & 18 & 14 \\
High school fields & 66 & 18 & 16 \\
College fields & 61 & 20 & 20 \\
Municipal fields & 60 & 20 & 19 \\
Professional league fields & 51 & 23 & 25 \\
\hline
\end{tabular}

\section{Conclusions}

This survey attempted to examine resident awareness of the currently enacted state-level pesticide ban in Connecticut. In addition, this study explored whether Connecticut residents feel state-mandated pesticide bans should be in place. Results indicate that awareness of the current pesticide ban is low among Connecticut residents, with few respondents correctly identifying the locations where the ban is currently mandated. In addition, most respondents believe that there should be a statewide pesticide ban. The primary locations where respondents support mandated pesticide bans are on school grounds and athletic fields.

The results suggest interesting educational, policy, and business implications. First, state or town administrators may benefit from increasing their educational efforts to raise awareness about existing pesticide bans. Policy makers need to educate Connecticut

Table 7. Marginal effects associated with the multinomial logit model to determine if characteristics of Connecticut residents affected whether they believed there should be a pesticide ban in Connecticut.

\begin{tabular}{|c|c|c|c|c|c|c|c|c|c|}
\hline & \multicolumn{9}{|c|}{ Should there be a pesticide ban? } \\
\hline & \multicolumn{3}{|c|}{ Yes } & \multicolumn{3}{|c|}{ No } & \multicolumn{3}{|c|}{ Not sure } \\
\hline & Marg. eff. ${ }^{\mathrm{z}}$ & SE & $P$ & Marg. eff. & SE & $P$ & Marg. eff. & SE & $P$ \\
\hline Caucasian & -0.018 & 0.047 & 0.705 & -0.013 & 0.032 & 0.678 & 0.031 & 0.043 & 0.465 \\
\hline Male & -0.049 & 0.036 & 0.175 & 0.105 & 0.027 & 0.000 & -0.055 & 0.034 & 0.102 \\
\hline Household income in 2015 & -0.000 & 0.000 & 0.360 & 0.000 & 0.000 & 0.285 & 0.000 & 0.000 & 0.753 \\
\hline Bachelor's or greater & 0.061 & 0.046 & 0.190 & 0.041 & 0.031 & 0.193 & -0.102 & 0.042 & 0.015 \\
\hline \multicolumn{10}{|l|}{ People in household (no.) } \\
\hline Adults & 0.015 & 0.016 & 0.359 & -0.023 & 0.011 & 0.040 & 0.007 & 0.016 & 0.634 \\
\hline Children ( $\leq 18$ years $)$ & -0.011 & 0.018 & 0.536 & 0.015 & 0.011 & 0.194 & -0.004 & 0.017 & 0.833 \\
\hline Maintain a landscape & 0.082 & 0.035 & 0.019 & 0.021 & 0.023 & 0.368 & -0.103 & 0.034 & 0.003 \\
\hline Republican & -0.080 & 0.049 & 0.108 & 0.038 & 0.033 & 0.257 & 0.042 & 0.048 & 0.384 \\
\hline Other & -0.041 & 0.038 & 0.280 & -0.015 & 0.026 & 0.562 & 0.056 & 0.037 & 0.127 \\
\hline $\begin{array}{l}\text { Trust information provided } \\
\text { by state government regarding } \\
\text { a pesticide ban }(0-100 \text { scale })^{\mathrm{y}}\end{array}$ & 0.002 & 0.001 & 0.002 & -0.001 & 0.000 & 0.001 & -0.001 & 0.001 & 0.276 \\
\hline $\begin{array}{l}\text { Political view on environment } \\
\quad(0-100 \text { scale })^{x}\end{array}$ & -0.002 & 0.001 & 0.013 & 0.001 & 0.000 & 0.007 & 0.001 & 0.001 & 0.362 \\
\hline Log pseudolikelihood & & \multicolumn{8}{|c|}{-986.665} \\
\hline$P>\chi^{2}$ & & \multicolumn{8}{|c|}{0.000} \\
\hline Pseudo $R^{2}$ & & \multicolumn{8}{|c|}{0.050} \\
\hline Observations (no.) & & \multicolumn{8}{|c|}{1,047} \\
\hline
\end{tabular}

${ }^{\mathrm{z}}$ Marginal effect.

${ }^{\mathrm{y}} 0=$ distrust, $50=$ neither trust nor distrust, $100=$ trust.

${ }^{\mathrm{x}} 0=$ extremely liberal, $50=$ neither liberal nor conservative, $100=$ extremely conservative. 
residents more about details of the already existing ban and at what locations the ban is mandated. Many residents have misguided perceptions about the exact locations where the pesticide bans are in effect. However, if policymakers choose to follow public sentiment, then extending the ban statewide to include ninth through 12 th grade school grounds and athletic fields, as well as to all publicly maintained parks, may become part of future Connecticut legislative dialogue.

Across the United States, as pesticide bans are considered or enacted, policymakers also need to understand the budget impact on cities/municipalities that must enforce the new bans. As noted by Bartholomew et al. (2015), most school grounds managers surveyed in 2012 indicated that the perceived quality of their school grounds/athletic fields decreased with the implementation of the pesticide ban, with $40 \%$ indicating that expenditures to maintain these properties increased. Passing legislation such as a pesticide ban can completely alter the management practices of those charged with maintaining school properties (Henderson et al., 2013), along with a decrease in understanding of acceptable alternative pest management practices (Campbell et al., 2018; Wallace et al., 2016). Many cities/municipalities currently work with limited and strict financial budgets. Increasing costs to manage properties without pesticides would severely affect towns if new restrictions were to be implemented at either a local or state level, with no increased funding to support the implementation of these restrictions. Any further pesticide restrictions should account for the need for safe playing surfaces, public health issues [e.g., ticks (Parasitiformes)], and the removal of problematic invasive weeds. Failure to have more than a singular focus (e.g., banning pesticides) without considering the consequences associated with the policy could have detrimental long-term effects to school districts, children's education outcomes, and health.

\section{Literature cited}

Alarcon, W.A., G.M. Calvert, J.M. Blondell, L.N. Mehler, J. Sievert, M. Propeck, D.S. Tibbetts, A. Becker, M. Lackovic, S.B. Soileau, R. Das, J. Beckman, D.P. Male, C.L. Thomsen, and M. Stanbury. 2005. Acute illnesses associated with pesticide exposure at schools. J. Amer. Med. Assn. 294:455-465.

Bachand, N. and L. Gue. 2011. Pesticide free? Oui! 2011 progress report: A comparison of provincial cosmetic pesticide bans. 28 July 2019. <https://davidsuzuki.org/ science-learning-centre-article/pesticidefree-oui-2011-progress-report-comparisonprovincial-cosmetic-pesticide-bans/>.

Bartholomew, C., B.L. Campbell, and V. Wallace. 2015. Factors affecting athletic field quality after pesticide bans: The case of Connecticut. HortScience 50:99-103.

Bassil, K.L., C. Vakil, M. Sanborn, D.C. Cole, J.S. Kaur, and K.J. Kerr. 2007. Cancer health effects of pesticides: Systematic review. Can. Fam. Physician 53:1705-1711.

Bellon, T. 2019. Explainer: What are the obstacles to Bayer settling Roundup lawsuits? 10 Nov. 2019. <https://www. reuters.com/article/us-bayer-glyphosatelawsuit-explainer/explainer-what-are-theobstacles-to-bayer-settling-rounduplawsuits-idUSKCNIVC11E>.

Campbell, J.H., J.J. Henderson, and V.H. Wallace. 2018. Comparison of presentation method effectiveness for dissemination of pesticide-free turfgrass management information. HortTechnology 28:536-542.

Chen, M., C. Chang, L. Tao, and C. Lu. 2015. Residential exposure to pesticide during childhood and childhood cancers: A meta-analysis. Pediatrics 136:719-729.

Connecticut General Assembly. 2009. Public Act 09-56. 2 Aug. 2019. <https://www. ct.gov/DEep/cwp/view.asp?A=2708\& $\mathrm{Q}=468812>$.

Connecticut General Assembly. 2015. Substitute Bill 1063. 2 Aug. 2019. <https://www.cga.ct.gov/2015/TOB/ S/2015SB-01063-R01-SB.htm>.

De Roos, A.J., A. Blair, J.A. Rusiecki, J.A. Hoppin, M. Svec, M. Dosemeci, D.P. Sandler, and M.C. Alavanja. 2005. Cancer incidence among glyphosate-exposed pesticide applicators in the agricultural health study. Environ. Health Perspect. 113:49-54.

Gilden, R., E. Friedmann, B. Sattler, K. Squibb, and K. McPhaul. 2012. Potential health effects related to pesticide use on athletic fields. Public Health Nurs. 29:198-207.

Greene, W.H. 2012. Econometric analysis. 7th ed. Prentice Hall, Upper Saddle River, NJ.

Hall, R. 2015. Anti-lawn care ban in Maryland leaves industry seeking answers. 31 July 2019. <https://www.turfmagazine.com/ lawn-care/anti-lawn-care-ban-in-marylandleaves-industry-seeking-answers $/>$.

Henderson, J., V. Wallace, and J. Campbell. 2013. Best management practices for pesticide free cool season athletic fields. 31 July
2019. <http://www.turf.uconn.edu/pdf/ research/factsheets/OrganicFields_BMP_ 2013.pdf?llr $=$ kaiit7cab\&oeidk $=a 07 \mathrm{e} 81 \mathrm{i} 48 \mathrm{ky}$ 01bfed07\&oseq $=\mathrm{a} 017 \mathrm{dfxg}$ jiuci $>$.

Hurley, J.A., T.A. Green, D.H. Gouge, Z.T. Bruns, T. Stock, L. Braband, K. Murray, C. Westinghouse, S.T. Ratcliffe, D. Pehlman, and L. Crane. 2014. Regulating pesticide use in United States schools. Amer. Entomologist 60:105-114.

Kowalewski, A.R., T.W. Stock, B.W. McDonald, C.M. Mattox, and B.L. Daviscourt. 2016. Developing and delivering a needs-based integrated pest management program for public school grounds employees. Natural Sciences Educ. 45:15-080017-ora. doi:10.4195/nse2015.0017.

Millington, B. and B. Wilson. 2014. An unexceptional exception: Golf, pesticides, and environmental regulation in Canada. Intl. Rev. Sociol. Sport 51:446-467.

Morgan, M.K., L.S. Sheldon, C.W. Croghan, P.A. Jones, G.L. Robertson, J.C. Chuang, N.K. Wilson, and C.W. Lyu. 2005. Exposures of preschool children to chlorpyrifos and its degradation product 3,5,6-trichloro-2-pyridinol in their everyday environments. J. Expo. Anal. Environ. Epidemiol. 15:297-309.

Niehoff, N.M., H.B. Nichols, A.J. White, C.G. Parks, A.A. D'Aloisio, and D.P. Sandler. 2016. Childhood and adolescent pesticide exposure and breast cancer risk. Epidemiology 27:326-333.

Ontario Ministry of the Environment. 2009. Ontario's cosmetic pesticides ban. 29 July 2019. <http://news.ontario.ca/ ene/en/2009/03/ontarios-cosmeticpesticides-ban.html>.

Owens, K. 2009. Schooling of state pesticide laws 2010 update. Pesticides and You 29:9-20.

Parrón, T., M. Requena, A.F. Hernández, and R. Alarcón. 2014. Environmental exposure to pesticides and cancer risk in multiple human organ systems. Toxicol. Lett. 230:157-165.

Sissell, K. 2005. New York city bans some pesticides on city property. Chemical Week 167:29. I Aug. 2019. <http://search. ebscohost.com/login. aspx ?direct $=$ true $\&$ $\mathrm{db}=$ edswsc\&AN $=000229201900024 \&$ site $=$ eds-live $>$.

U.S. Census Bureau. 2019. American fact finder U.S. Census Bureau, 2013-2017 American Community Survey 5-Year Estimates. <https://factfinder.census.gov/ faces/nav/jsf/pages/community_facts. xhtml? src $=$ bkmk $>$.

Wallace, V., C. Bartholomew, and J.H. Campbell. 2016. Turf manager response to changing pesticide regulations. HortScience 51:394-397. 